\title{
OFFICE QUALITY CLASSIFICATION THEORETICAL AND EMPIRICAL ISSUES
}

\author{
Ganiyu Onatunde OLAYONWA ${ }^{1 凶}$, Abdul Hamid Mar IMAN ${ }^{2}$ and Suriatini ISMAIL ${ }^{3}$ \\ ${ }^{1}$ Universiti Teknologi Malaysia - Property Management, 81310 UTM Skudai , Skudai, Johor \\ 81310, Malaysia \\ E-mail: goolayonwa2@live.utm.my \\ ${ }^{2}$ Universiti Teknologi Malaysia - Property Management, 81310 UTM Skudai , Skudai, Johor \\ 81310, Malaysia \\ E-mail: hamidman@utm.my \\ ${ }^{3}$ Universiti Teknologi Malaysia - Property Management, 81310 UTM Skudai , Skudai, Johor \\ 81310, Malaysia \\ E-mail: suriatini@utm.my
}

Received 20 February 2011; accepted 31 August 2011

\begin{abstract}
Office quality classification literature recognises identification of office classes through division of office market rent distribution into intervals but failed to provide sound theoretical framework and comprehensive empirical approach to this method. This paper theorised that as office rental levels are a function of office quality; high quality office classes should have their mean rents greater than average market rent and mean rents of low quality classes. Also that heterogeneous nature of property coupled with lack of perfect information to market participants could result into differential evaluation of rent and quality of the same property by different market participants. The behaviour of participants normally reflects in distribution of market rent by depicting natural breaks in the distribution that could be captured by univariate data exploration. Frequency and histograms of rent distributions that were assumed to depict the behaviour of market participants were used to divide rent distribution to intervals to identify office quality classes. The results of this classification were validated by discriminant analysis. $67 \%$ and $59 \%$ accuracies were achieved for estimation and holdout subsamples respectively. This paper extended theoretical and empirical approaches in office quality classification. The proposed empirical approach could be used in future classification research.
\end{abstract}

KEYWORDS: Office quality; Frequency histogram; Classification; Discriminant analysis; Validation

\section{INTRODUCTION}

The general problem of lack of available data on commercial property accounted for lag in research efforts in office classification as compared to housing sector (Dunse et al., 2001; Nappi-Choulet et al., 2007). This lag has resulted into adoption of methodological approaches in housing literature in research effort in commercial properties (Dunse et al., 2001). The general effect of this situation is less developed theoretical and empirical approaches in office classification. Literature on office quality classes (Dunse and Jones, 2002; Fuerst, 2007) usually reported real 
estate agents views of office quality classes that were not based on sound theories and comprehensive empirical approaches. The few documented empirical approaches were not based on any theoretical framework and were also based on the subjective opinion of the analysts which made them to be ad hoc in outlook.

Therefore office quality classification approaches have been subject of criticisms from some authors. Ho et al. (2005) argued that office quality classification methods were descriptive and devoid of quantitative analysis. Also Corona (2003) and Imperiale (2006) argued that office quality classification studies were subjective; and Duggan (2003) argued that office quality classification methods were less scientific.

One of the problems of office quality classification that might have formed the basis of the criticism might include the approach of grouping offices into quality classes based on office age (Dunse and Jones, 2002; Graham and Bible, 1992) which might not reflect the true quality condition of office buildings and variations in maintenance standard.

Some studies that involve qualitative classification only described quality standard of attributes but failed to present the methods of aggregating the qualities of all the attributes to identify quality classes (BOMA, 2011; Daud et al., 2010; Daud et al., 2011; Fuerst, 2007; Graham and Bible, 1992; Ling and Archer, 2006; Property Council of Australia, 2006; and Property Council of New Zealand, nd). Descriptive office quality classification based on rent intervals (Downs, 1980; Roberts, 1986; Graham and Bible, 1992; Ling and Archer, 2006; BOMA, 2011; Dermisi and McDonald, 2010), did not report the theoretical basis and empirical method used to identify office quality classes. They only give description of rent levels for each of the office classes.

Therefore, the focus of this paper is to develop theoretical framework and comprehensive empirical approach of using office rent levels to classify offices into quality classes. In line with the focus, attempts will be made to provide answers to the following questions:

How can rent-office quality theories and behavior of office market participants be combined to adequately portray the relationship that identifies office quality classes?

How can this relationship be transformed into empirical method to classify offices into quality classes?

How can office attributes be combined into a linear model that can adequately validate procedure of rent-interval office quality classification?

To what extent are offices quality classes identified through rent-quality level are valid?

The specific objectives are to:

Propose theoretical framework and empirical method for office quality classification.

Use the proposed empirical method to classify offices in Abuja (Federal Capital City of Nigeria) into quality classes.

Use linear model that combines office characteristics to assess accuracy of classification results and validate the classification procedure.

The following hypotheses will be tested:

If rent is a true reflection of office quality, therefore office quality rent-interval classification should be able to identify high quality office classes with mean rents greater than average market rent and mean rents of low quality office classes.

If rent is a function of qualities of office attributes; adequacy of results of rent-quality classification could be measured by the percentages by which predicted accuracies of results are greater than accuracies that could be associated to chance occurrences as predicted by linear model that combines all office attributes.

The remaining sections of this paper are arranged in the following order: section two reviews property value and submarket segmentation theories; section three presents the 
proposed theoretical framework; section four presents the proposed empirical approach to rent-quality classification; section five discusses linear model to validate classification procedures; section six presents the methodology, section seven presents the results of rent-interval classification and validation; while section eight presents discussion and conclusion.

\section{REVIEW OF PROPERTY VALUE AND CLASSIFICATION THEORIES}

This section reviews previous classification studies that used property values as basis of classifying properties into homogenous subgroups that form the background of the proposed theoretical framework in this paper. Despite variations in approaches to property classification the common variable to all the approaches is property value. Therefore, most empirical approaches of assigning properties into homogenous subgroups were based on identification of differences in property values within property market (Adair et al., 1996). Supply cost, immobility of property together with inelasticity of demand for attributes could account for variation in property values within property market (Bajic, 1983). Imperfect market could result into multiple value disequilibria within a property market (Dunse et al., 2001; Dunse and Jones, 2002), that could also result into variations in property values within the market. Division of housing market in neighbourhood line was based on theory of inelastic demand of public goods and externalities that could lead to variation in prices of property in a property market (Bajic, 1983). Therefore properties with relatively similar values within property market were normally classified into homogenous subgroups. Varying qualities of structural characteristics of properties were the basis of substituting the structural characteristics of properties by both users and developers to determine qualities and values. This behaviour of users and developers were used to group properties into similar subgroups by hedonic model analysis (Rothenberg et al., 1991; Adair et al., 1996). The next section discusses the proposed theoretical framework that drew from these theories of property market segmentation.

\section{THE PROPOSED RENT-QUALITY CLASSIFICATION THEORETICAL FRAMEWORK}

This section discuses the proposed theoretical framework upon which the analysis section is based. The theory of substitutability that was the basis of dividing property into quality types is more related to this study. However, empirical identification of properties that could be close substitutes to both users and developers could pose problem in application of substitutability theory. Therefore utility theory of value that could divide property into quality levels and lack of adequate information in property market to market participants coupled with their subjective evaluation of rent and quality normally results into different evaluation of values and quality by market participants.

The basic economic theory stated that the higher the utility the higher would be the returns. This could be found in the observations that returns to a property were a direct function of the quality of the property (Baum, 1994). Rental levels were also found to be good indicators of office qualities (Graham and Bible, 1992; Chung and Hui, 2009). Therefore rent-quality model could be represented mathematically thus:

$$
\mathrm{R}=f(\mathrm{Q})
$$

where: $\mathrm{R}$ - net rent; $\mathrm{Q}$ - overall building quality.

Figure 1 is the graphical representation of rent-quality model that is similar in shape to the shape of supply curve which slopes from 
right to left. Movement along the rent-quality line indicates changes in qualities that resulted into changes in rents. Movement from quality $\mathrm{Q}_{1}$ to $\mathrm{Q}_{2}$ resulted into rent increases from $R_{1}$ to $R_{2}$.

Heterogeneity nature of real properties that could make one property to be different from the others; coupled with imperfect nature of property market that is characterised by inadequate information were responsible for interval estimation of values as against point estimation of values by valuers, users and investors. Rental values could not be estimated with certainty as complete information on property transactions was not always available; this coupled with imprecision that might be associated with human evaluation of property qualities could make point estimation of value to be difficult. In a developed market where agency services involve dissemination of information on property transactions and value assessment, there is tendency to have many market participants (informed participants) to evaluate properties with approximate equal qualities to have approximately equally rental value. While few uninformed market participants would likely under-evaluate or over-evaluate the rents of properties of approximately equal qualities in the market.
Frequency histograms are more adequate in compressing large data set to provide better visual clue on natural groupings than frequency tables. Therefore plotting the frequency distribution of rent on histogram based on the behaviours of market participants, would show multi-modal bars that represent various quality classes assessed to have the same rental value by majority of informed participants. There could be histogram bars with few properties before and after the modal bars that might not have enough number of offices to categorise them into a distinct groups. These bars might represent frequencies of offices whose qualities and rents were either under or over evaluated by uniformed tenants and landlords. Therefore division of market rent distribution into rent intervals to capture the behaviours of the market participants to group properties into quality classes may involve use of unequal rent intervals that may embrace many histogram bars.

Therefore vertical axis of Figure 1 that represents quality could be changed to represent frequency axis to plot frequency histograms of properties that possess the respective quality at the respective rental levels. Frequencies for the different rental values are determined by estimating the numbers of properties that that

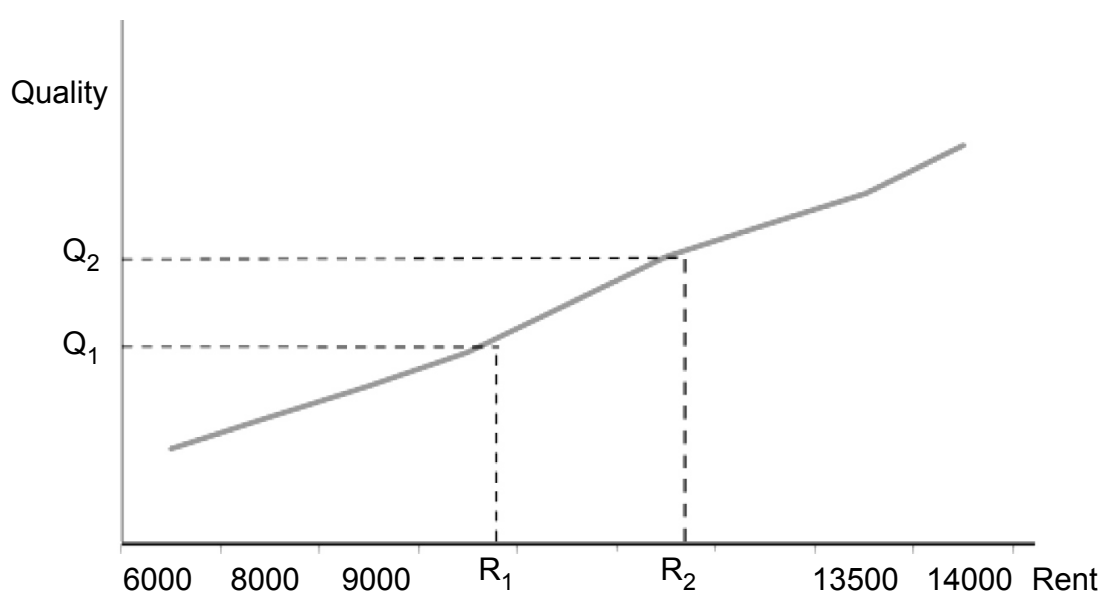

Figure 1. Rent-quality chart 
have the same rental value. The histogram bars could then be grouped according to the behaviour of market participants to identify property quality classes. The modification to Figure 1 is depicted in Figure 2.

The lowest quality class is between rent intervals of 5000 and 8000 and the second highest quality class is between the rent interval of 9000 and 11000 and the highest quality class is between rent intervals of 12000 and 14000 . To reduce human subjectively in division of market rent distribution into intervals the concepts of exploratory data analysis as applicable to univariate classification could be used to empirically divide rent axis into intervals to identify office quality classes. Empirical method to this theoretical framework is the subject matter of discussion in the next section.

\section{PROPOSED EMPIRICAL APPOACH TO RENT-QUALITY CLASSIFICATION}

To reduce human bias associated with a priori classification, the empirical approach to identify office quality classes based on proposed theories requires application of exploratory data analysis used in univariate classification. Basically it involves identification of natural breaks in data distribution that could divide univariate data into intervals to group a variable into homogenous groups (Wyatt and Ralphs, 2003). The applications mainly use frequency distribution, histogram and univariate analysis. Frequency distribution tables and frequency histograms reveal patterns in a data that portray the grouping of occurrences of similar objects (Cooper and Schindler, 2006). Histograms consists of contiguous horizontal or vertical bars drawn from either horizontal or vertical bins called intervals, classes or groups; with each bar representing the numbers of objects with similar values (Verde and Irpino, 2007). Histograms provide information on the shape of data distribution that could provide visual clues on the possible numbers of subgroups. Multimodal histograms could suggest presence of subgroups in a data; also detached bars from continuous histograms bars could suggest outliers or subgroups; large differences in adjacent rows or columns of frequency distribution table or adjacent bars of histograms could suggest subgroups (Cooper and Schindler, 2006). Identification of homogenous group is one aspect of classification; the other aspects are to ascertain that the groups are actually different in terms of grouping variable and

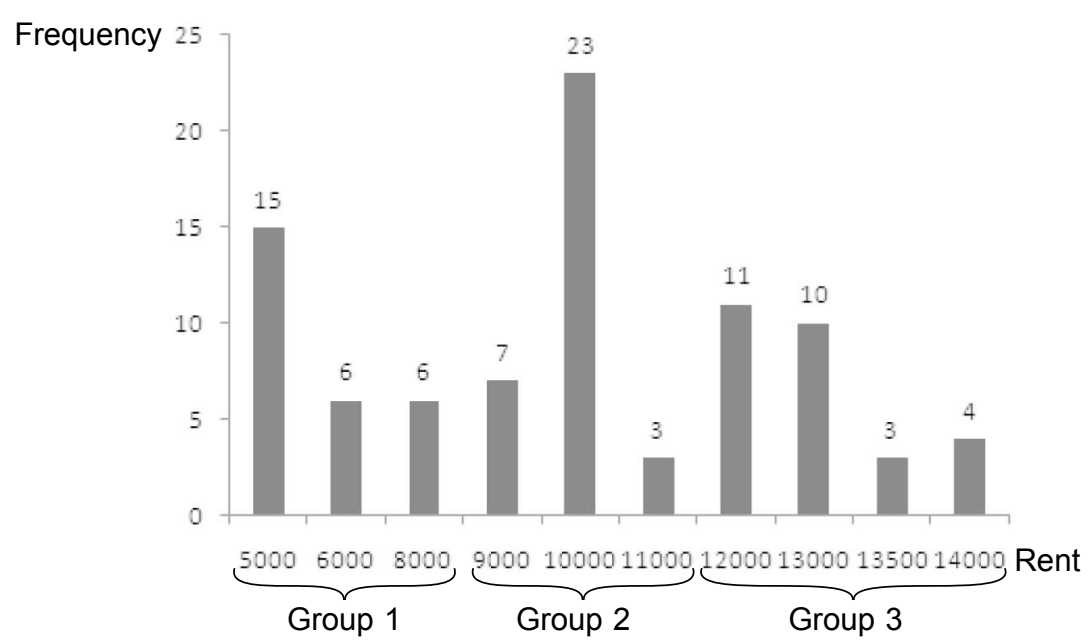

Figure 2. Grouping of similar properties based on rent intervals 
that classification procedures are valid. The usual approach to ascertain that the group are different in terms of classification variable is to test for differences in group means.

Ascertaining the groups differences require univariate analysis that assesses differences in group means (Everitt, 1993; Sharma, 1995). Univariate analysis that uses $F$ ratios to test the differences in group means assesses whether groups identified are actually different on the variable that was used to classify them (Hair et al., 2005). Next subsection is devoted to development of linear model that combines property characteristics for validation of rent-quality classification procedures.

\section{LINEAR MODEL TO VALIDATE CLASSIFICATION PROCEDURES}

The aim of developing the linear model is to evaluate the level of accuracy of rent-interval classification with accuracy of classification results when all factors that contribute to rental levels are taken into consideration. Property value contribution theory is based on the assumption that various characteristics of property contribute to the total value of the property. As property value could be taken to be an indicator of quality, therefore quality of a property is a function of contribution of quality of various property attributes. Therefore adequacy of rent-quality classification could be measured by percentage of quality group membership that could be correctly predicted by linear model that combines all property characteristics for prediction and classification purposes. The characteristics of office property that contribute to values had been identified to be location, quality of physical characteristics and quality of facilities (Baum, 1994; Ho et al., 2005; Vilnai-Yavetz et al., 2005; Fuerst, 2007). The statistical model that satisfies these requirements is discriminant analysis. Table 1

Table 1. Variables description

\begin{tabular}{|c|c|c|}
\hline Variable & Symbol & Description \\
\hline Rent & Rent & Net asking rent per metre square in Nigerian currency. \\
\hline Gross floor area & GArea & $\begin{array}{l}\text { Total sum of effective usable floor areas and common areas for all the floors } \\
\text { in an office building. }\end{array}$ \\
\hline Net floor area & NArea & Total sum of effective usable floor areas for all the floors in an office building \\
\hline Number of floors & $\mathrm{Nfl}$ & Total number of floor per office building. \\
\hline Location & Loca & $\begin{array}{l}\text { Attributes included agglomeration, access road quality, public } \\
\text { transportation, security and safety of neighbourhood and proximity to } \\
\text { complementary uses. }\end{array}$ \\
\hline $\begin{array}{l}\text { Façade } \\
\text { presentation }\end{array}$ & Facpr & $\begin{array}{l}\text { Aesthetic qualities of arrangement of structural elements (outer beams, } \\
\text { columns and railings), window and door openings; quality of finishes and } \\
\text { maintenance standard. }\end{array}$ \\
\hline $\begin{array}{l}\text { Internal } \\
\text { presentation }\end{array}$ & Inpre & $\begin{array}{l}\text { Attributes included aesthetic quality finishes of internal walls, floors, } \\
\text { ceilings and their maintenance standard. This only for common areas like } \\
\text { entrances lobby and passages. }\end{array}$ \\
\hline Functionality & Func & $\begin{array}{l}\text { Attributes are level of open floor design, adequacy of separation of common } \\
\text { areas from users workspaces, adequacy of way-finding elements (directional } \\
\text { landmarks and signs) and adequacy of conference room. }\end{array}$ \\
\hline Services & Sevr & $\begin{array}{l}\text { The attributes are sources and adequacy of supply of electricity, ventilation } \\
\text { system, information technology system (IT); and adequacy of internal } \\
\text { circulation system (lifts, stair cases passages and lobbies). }\end{array}$ \\
\hline $\begin{array}{l}\text { Surrounding } \\
\text { quality }\end{array}$ & Surq & $\begin{array}{l}\text { The attributes included quality of car park, aesthetic quality of } \\
\text { landscaping, cleanliness. }\end{array}$ \\
\hline $\begin{array}{l}\text { Management } \\
\text { quality }\end{array}$ & Manql & $\begin{array}{l}\text { The attributes are users' assessment of effectiveness of property manager } \\
\text { and promptness of manager to the request. }\end{array}$ \\
\hline
\end{tabular}


contains the summary description of variables that are used to develop the discriminant analysis linear model used in this paper. The dependent variables used in estimation of discriminant analysis in this study are nominal scores of 1- 4 assigned to office classes A, B, C, and $\mathrm{D}$ respectively, the classes were identified through the initial rent-interval classification. The first set of independent variables used in this study are net asking rent (in Naira (N) Nigerian currency), gross floor area and net floor area (measure in square metres) number of floors that were extracted from records of the offices surveyed. The second set of independent variables are those assessed by data collection panels which included location, façade presentation, internal presentation (common areas), functionality, services, surroundings quality and management quality.

Discriminant analysis model is used because is a linear combination of independent variables that maximizes the ratio of betweengroup sum of squares $\left(\mathrm{SS}_{\mathrm{b}}\right)$ and within-group sum of squares $\left(\mathrm{SS}_{\mathrm{w}}\right)$ so as to achieve maximum separation between a priori groups (Hair et al., 2005; Sharma, 1995).

Discriminant analysis model is represented by equation 2 .

$$
\begin{aligned}
& \mathrm{Z}_{\mathrm{ik}}=\alpha+\beta_{1} \text { Garea }_{1 \mathrm{k}}+\beta_{2} \text { Nofl }_{2 \mathrm{k}}+\beta_{3} \text { Narea }_{3 \mathrm{k}}+ \\
& \beta_{4} \text { Loca }_{4 \mathrm{k}}+\beta_{5} \text { Facpr }_{5 \mathrm{k}}+\beta_{6} \text { Inpre }_{6 \mathrm{k}}+ \\
& \beta_{7} \text { Func }_{7 \mathrm{k}}+\beta_{8} \text { Serv }_{8 \mathrm{k}}+\beta_{9} \text { Surql }_{9 \mathrm{k}}+ \\
& \beta_{10} \text { Manq }_{10 \mathrm{k}}
\end{aligned}
$$

where: $\mathrm{Z}_{j k}$ - discriminant $\mathrm{Z}$ score of discriminant function $j$ for object $k$; $\alpha$-intercept; $\beta_{i}$ discriminant weight for independent variable $i$; $\mathrm{X}_{i k}$ - independent variable $i$ for object $k$.

$\mathrm{Z}_{i k}$ is the discriminant score of case $i$ on the discriminant function $k$. It is calculated by using un-standardized discriminant loadings or weights. Z scores are used to predict cases into appropriate groups by comparing the scores with the cutoff scores. $\beta_{i k}$ is the discriminant weight for case $i$ on discriminant function $k$.
$\mathrm{X}_{i k}$ is the raw scores of case $i$ on discriminant function $k$.

The basis of predicting membership of a priori groups using discriminant analysis involves division of discriminant space into mutually exclusive and collectively exhaustive regions by the cut-off scores. Prediction involves computation of total discriminant score of each case and then assigning the case to the region to which the value of its score falls. If the means of the groups to be predicted are on a straight line, the line dividing the groups will be parallel to the discriminant space thereby forming intervals along the discriminant space (Sharma, 1995). Figure 3 is graphical representation of division of discriminant space of four groups having their means on a straight line.

Figure 3 indicates that statistical model uses division of discriminant space into intervals to classify and predict objects into the intervals their scores fall; which is more related to rent-quality classification approached developed in section 4.The division of market rents to intervals to identify property quality groups might correspond with partitioning of discriminant space to identify property quality groups; therefore discriminant model should be able to predict group membership of rentquality groups. The implementation of the rent-quality classification approach and validation linear model developed in sections four and five respectively are the subject matter of the rest part of this paper.

\section{THE STUDY AREA AND DATA DESCRIPTION}

This section presents overview of the study area and description of data used in analysis.

\subsection{The study area}

The Federal Capital City (FCC) Abuja the main administrative city of the Federal Capital Territory (FCT) of Nigeria is the study area. 


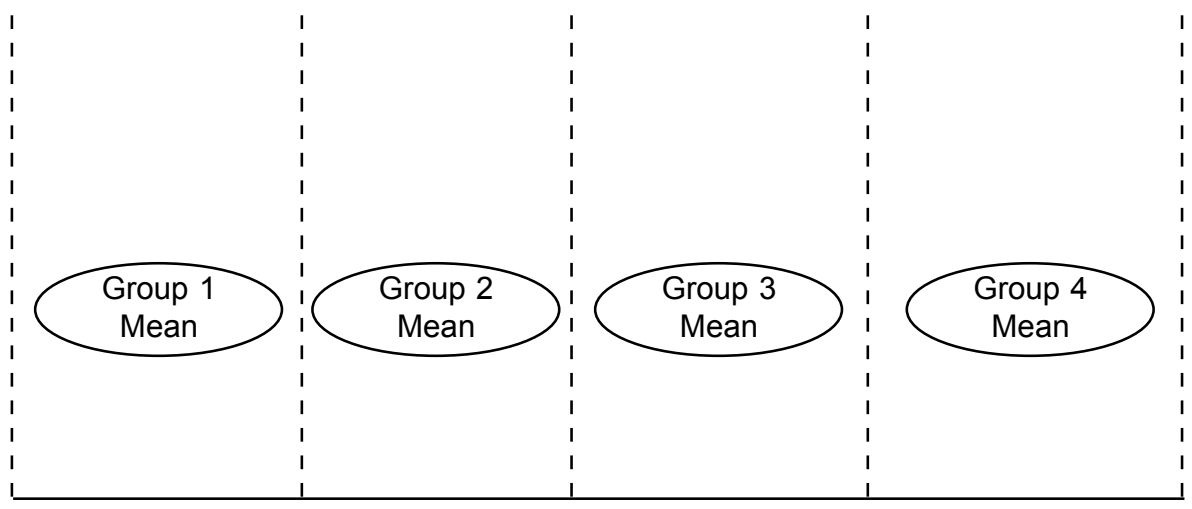

Discriminant Space

Figure 3. Interval partitioning of discriminant space of four groups with means on a straight line (Sharma, 1995)

FCT lies between latitude $8^{\circ} 25^{\prime \prime} \mathrm{N}$ and $9^{\circ} 20^{\prime \prime}$ $\mathrm{N}$ of the equator and longitude $6^{\circ} 45^{\prime \prime} \mathrm{E}$ and $7^{\circ}$ 39" E of the Greenwich meridian. Abuja has a landmass of about 8,000 sq. $\mathrm{km}$ out of which the city itself occupies about $250 \mathrm{sq}$. $\mathrm{km}$. The Federal Capital City, designed as a model national capital city, was to accommodate a half a million people when fully developed; today it accommodates nearly one and a half million people. National Population census of 1991 indicated that the city accommodates about 1.2 million people; while in 2006 national population census figure, FCT population stands at 1.4 million. Abuja replaced Lagos as the Capital of Nigeria in December 1991. There are six local council areas in FCT among them is the Municipal Area Council that accommodated the Federal Capital City.

The Federal Capital City was to be developed in phases according to the Master Plan. The phases are divided into districts, the topology of the districts are shown in Figure 4. The first three phases have been developed substantially while the other phases are yet to be developed. Phase 1 area of the city is divided into five (5) districts. These are the Central Business District (CBD), Garki, Wuse, Maitama, and Asokoro.
There are also five districts in Phase 2. They are Kado, Durumi, Gudu, Utako and Jabi. And the Phase 3 districts are Mabuchi, Katampe, Wuye and Gwarimpa. This study covers all districts in phase 1 and Utako and Jabi districts in phase 2 of the Federal Capital City that have substantial commercial development.

Movement of Federal Government Ministries and foreign embassies from Lagos to Abuja in 1991 resulted into rapid development of offices in the Federal Capital City. Many private business organizations in Lagos and other parts of the country relocated to Abuja or opened branch offices for easy contact with the ministries. This resulted into rapid development of offices by private sectors to profit from high demand for office spaces.

\subsection{Data description}

The data used for this study are samples of 250 office blocks from the list of surveyed offices in Abuja the Federal Capital City of Nigeria between January and April 2010. Five trained assessors who are professionals in real estate were used to collect the data as there were no available databases on offices in the study area. Moreover some variables require on site assessment of their present conditions. 


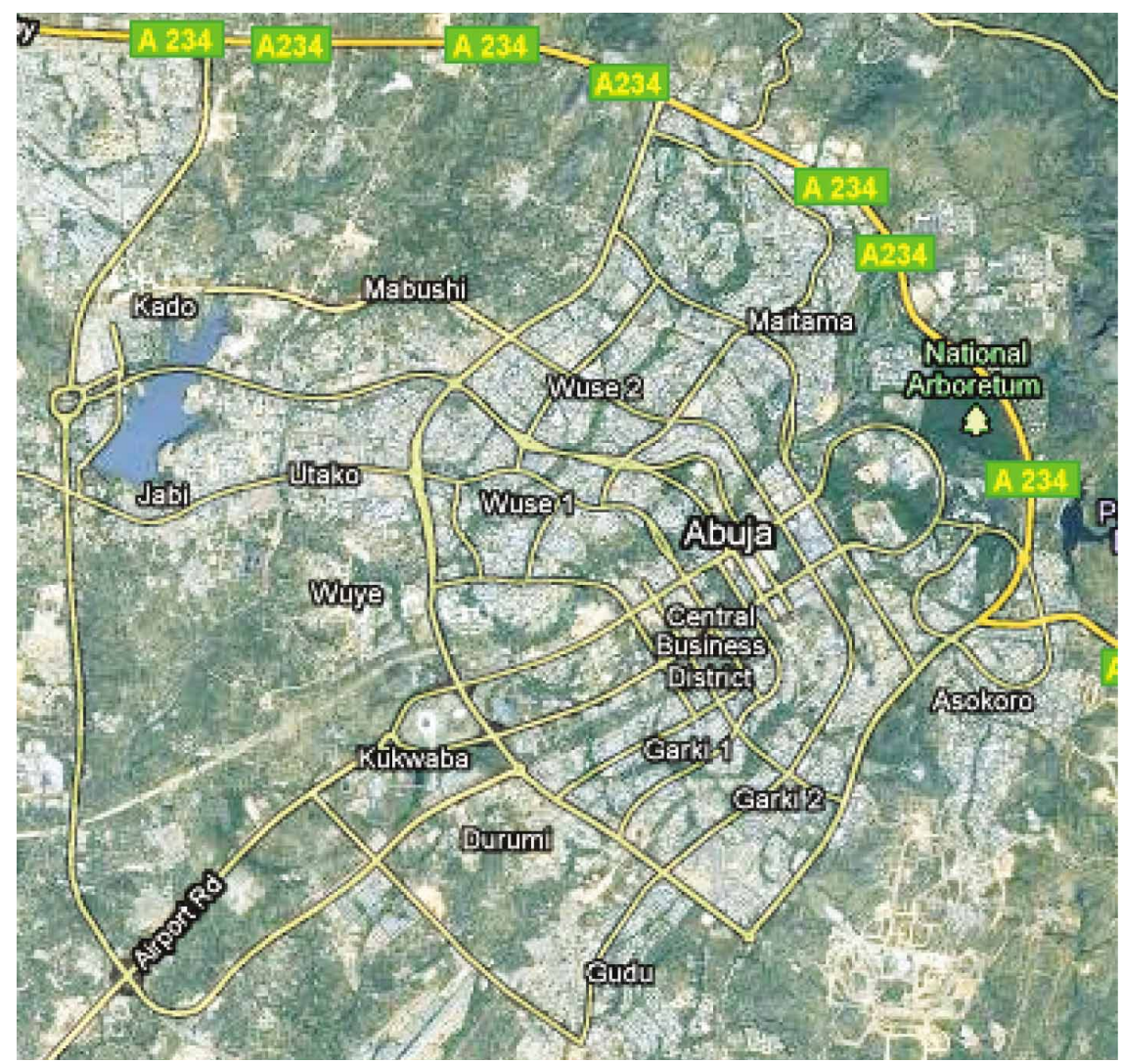

Figure 4. Google Map of districts in Federal Capital City of Abuja (adapted from Google Map 2010)

This approach was in line with Bishop (1977) and Rider Hunt (1991) approaches used to assess quality of building attributes. Bishop (1977) used visual appraisal to rate quality of buildings on seven point scale ranging from highly appropriate to very inappropriate. Rider Hunt (1991) used experts to assess CBD office buildings on ten points rating scale through site inspection. Also Adair et al. (1996) used field survey and continuum scale of $1-5$ to assess qualities of housing attributes. Table 2 presents the summary statistics of the data.

\section{METHODOLOGY}

Offices were grouped into quality classes based on rental levels. Office rent frequency distribution and frequency histograms were used to examine natural breaks in the data to divide the market rents into appropriate intervals. Frequency table was constructed for office rental values distribution which grouped the number of cases falling into each of the rental values together. This showed rental values with high office frequencies and some rental values with low office frequencies. Office frequency was considered to be high if the number of offices is above thirty as most statistical analysis requires thirty cases to be valid. The rental values that were having low offices frequencies were grouped with adjacent high office frequencies where they could not form a distinct group or were grouped together to form a distinct group where there number is greater than thirty. 
Table 2. Summary statistics of the data

\begin{tabular}{|c|c|c|c|c|c|c|c|c|c|c|c|c|}
\hline & & Rent & Garea & Narea & Nofl & Loca & Facpr & Inpre & Func & Serv & Surql & Manql \\
\hline \multirow[t]{2}{*}{$\mathrm{N}$} & Valid & 250 & 250 & 250 & 250 & 250 & 250 & 250 & 250 & 250 & 250 & 250 \\
\hline & Missing & 0 & 0 & 0 & 0 & 0 & 0 & 0 & 0 & 0 & 0 & 0 \\
\hline \multicolumn{2}{|l|}{ Mean } & 20088.8 & 2443.2 & 1981.7 & 3.2 & 56.9 & 30.3 & 48.2 & 59.0 & 171.1 & 25.9 & 41.4 \\
\hline \multicolumn{2}{|c|}{ Std. Deviation } & 8355.7 & 1427.7 & 1286.0 & 1.4 & 11.1 & 4.9 & 7.5 & 14.8 & 17.5 & 2.75 & 8.1 \\
\hline \multicolumn{2}{|l|}{ Minimum } & 5000.0 & 350.0 & 295.0 & 1.0 & 33.7 & 16.3 & 22.0 & 11.3 & 121.0 & 16.5 & 19.3 \\
\hline \multicolumn{2}{|l|}{ Maximum } & 40000.0 & 5575.0 & 4874.0 & 7.0 & 71.0 & 39.9 & 61.7 & 88.2 & 199.3 & 34.3 & 62.9 \\
\hline \multirow[t]{3}{*}{ Percentiles } & 25 & 14750.0 & 1345.0 & 977.3 & 2.0 & 44.9 & 26.6 & 42.5 & 46.4 & 159.7 & 24.6 & 34.4 \\
\hline & 50 & 20000.0 & 2148.0 & 1656.0 & 3.0 & 61.4 & 31.4 & 49.4 & 56.1 & 172.6 & 26.3 & 42.0 \\
\hline & 75 & 25000.0 & 3160.8 & 2756.0 & 4.0 & 67.1 & 34.2 & 55. & 72.2 & 186.1 & 27.8 & 47.4 \\
\hline
\end{tabular}

The lowest office rent in the study area is $\$ 5000$. Within the rent interval of \$5000 $\$ 14500$ no rental value has a frequency of up to 30 offices, the maximum office frequency within this rent interval is 23 , therefore offices in this rent range were grouped to form office quality class D. The rent of 15000 has a frequency of 41 offices which is greater than 30 offices that could make the offices to form a distinct class. But because within the rent interval of $\$ 15000$ - $\$ 19500$ the second highest office frequency is 15 , therefore office frequencies within the rent range of $\$ 15000-$ N19500 were grouped together to form office quality class $\mathrm{C}$. At rent point of $\$ 20000$ office frequency is 46 ; therefore offices at this rental value were not grouped with office quality class C. The rent forms the lower boundary of rent interval for Class B. Frequency of offices within rent interval of $\$ 20000-\$ 245000$ were grouped together to form quality class B as the second highest office frequency in this rent range is 13 . Rent of $\mathrm{N} 25000$ has office frequency of 50, therefore offices at this rent point were not grouped within office quality Class B but the rent formed the lower boundary for office quality Class A. The rent interval for office quality class A is between $\$ 25000$ $\$ 40000$ as rent of $\$ 40000$ is the highest rental value in the study area. Although at the rent of $\$ 30000$ frequency of office is 35 that could have made the offices at this rental value to be considered a distinct class, but assessment of results accuracy and validation indicated that four quality classes were better than five office quality classes.

Frequency histogram was also constructed based on the rent intervals of these initial groups to depict the frequencies graphically in order to assess the extent the initial groups represent multimodal histogram bars. The rent intervals from this initial classification were used as class intervals for plotting the histogram. The histogram represented multi-modal bars that represented distinct subgroups. To be sure that the resulting groups were actually different, One-way analysis of variance was used to test the group mean differences.

Stratified random sample was used to select 250 offices from the list of offices assessed to represent different quality groups; which is a condition in estimation of discriminant analysis. The stratification variable was a priori classes A, B, C, and D; and random samples were taken from each class in proportion to the size of its class in the sample frame. Offices in Class A has a total sample of 93 offices, those in 
Class B, with a total sample of 52 offices, those in Class C, with a total sample of 42 , while the total samples for Class D is 62 . The total sample size was considered adequate because it is 25:1 ratio of observations to independent variables, which is greater than 20:1 ratio of observations to independent variables recommended by Hair et al. (2005) and Stevens (2002). To validate the classification procedure the sample of 250 offices was further divided into 150 estimation subsamples and 100 holdout subsamples. Validation of classification procedure was done by classifying fresh cases in holdout subsamples that were not included in the initial estimation of discriminant analysis and by comparing the results accuracy with standard measures of accuracy. This assesses the consistency of classification procedure.

Discriminant analysis estimation was used to assess classification accuracies and validate classification procedures. SPSS statistical package was used to estimate discriminant functions by assigning numbers $1-4$ to initial quality classes in order of highest quality classes to lowest quality classes to form dependent variables to be entered into SPSS discriminant procedure. This was followed by simultaneous entering of all independent variables from the combined selected subsamples from the initial four quality classes. Stepwise method was not used as it could remove from initial analysis independent variables that are highly correlated which could have substantive contribution to discriminating power of the functions in the final analysis. Prior probability option for classification was selected so that classification could be based on group size as the office classes varied in sizes. Classification was also based on separate co-variance matrices option as the classes had unequal co-variance matrices. Violation of the assumption of equal co-variance matrices requires the use of separate co-variance matrix in classification and cross-validation of classification procedure by using separate samples from the samples used to estimate discriminant functions (Johnson and Wichern, 2002; Stevens, 2002; Tabachnick and Fidell, 2006). The next section presents the results of rent-interval classification and discriminant analysis estimation of classification accuracies and validation of classification procedures.

\section{RESULTS OF OFFICE QUALITY RENT-INTERVAL CLASSIFICATION AND VALIDATION}

Four office quality classes were identified through rent-interval classification in the study area. Estimation of classification accuracies and validation of classification procedure indicated that $66.7 \%$ of offices in estimation subsamples were correctly classified, while $59 \%$ of offices in the holdout subsamples were correctly classified. The accuracies' percentages are greater than percentages of accuracies that could be attributed to chance occurrences. The details are presented in the subsections below.

\subsection{Results of office quality rent-interval classification}

Table 3 presents the results of office quality rent-interval classification. 93 Offices classified into Class A have the highest quality in the market with the highest mean rent of N28815.00 per square metre which is higher than the market mean rent of $\$ 20206.00$ per square metre and sample mean rent of $\$ 20088.80$ per square metre. The rent range for offices in class A is between $\$ 25000.00$ and $\$ 40000.00$ per square metre.

52 offices classified into Class B ranked next to class A offices with average rent of N20759.00 which is above average of both market mean rent and sample mean rent with rent range of between $\$ 20000.00$ and N24500.00. 43 offices classified into Class C are 
of lower quality to class B offices with average rent $\$ 15963.00$ lower than the average market rent and the sample mean rent with rent range between $\$ 15,000.00$ and $\$ 19500.00 .62$ Offices classified into class D have the lowest mean rental value of $\$ 9298.00$ lower than both the market and sample mean rents with rent range between $\$ 5000.00$ and $\$ 14500.00$. Differences in mean rents of office quality classes are reflection of differences in qualities among the classes. The $F$ statistics was 530.23 and was significant at 0.00 level of significance and Scheffe post hoc multiple comparisons of the class means were all significant at 0.00 level of significance. All these suggested that the a priori classes were distinct and optimal.

Table 3. Rent-interval classification result

\begin{tabular}{lllll}
\hline Class & $\begin{array}{l}\text { No in } \\
\text { class }\end{array}$ & $\begin{array}{l}\text { Rent class } \\
\text { means }\end{array}$ & \multicolumn{2}{l}{ Rent range } \\
\cline { 4 - 5 } & & & $\min$ & $\max$ \\
\hline $\mathrm{A}$ & 93 & 28815.05 & 25000.00 & 40000.00 \\
$\mathrm{~B}$ & 52 & 20759.62 & 20000.00 & 24500.00 \\
$\mathrm{C}$ & 43 & 15962.79 & 15000.00 & 19500.00 \\
D & 62 & 9298.39 & 5000.00 & 14500.00 \\
Total & 250 & 20088.80 & 25000.00 & 40000.00 \\
\hline
\end{tabular}

Before these classification results could be considered to be authentic and discussed, the procedures had to be validated by assessing classification accuracies using discriminant analysis predictive model. The next subsection presents the validation of result of this initial classification.

\subsection{Validation of classification results by discriminant analysis}

The standards by which classification accuracies are compared are values of maximum and proportional chance criteria plus a quarter of each of their values and also by comparing estimated Press's Q statistics with Chi Square value at 1 degree of freedom (Hair et al., 2005). If the values of classification accuracies are greater than the values of these standard measures, the classification results could be considered to be adequate. Maximum chance criterion is the percentage of cases in the largest group. The underlying assumption in its use is that there is tendency that unguided assignment of cases to group could result into all cases being assigned to the group that has the highest percentage of probability. Proportion chance criterion assumes equal probability of cases being assigned to groups. It is the summation of the square percentages of cases in each of the groups. Chi square statistics at 1 degree of freedom is the value of classification accuracy that is assumed to be attributed to chance occurrence and is $6.63 \%$.

Three discriminant functions were estimated as there were four groups since the numbers of possible discriminant functions is either numbers of groups minus one or the number of independent variables (Hair et al., 2005; Tabachnick and Fidell, 2006). The test of practical significance indicated that the three were significant with function 1 having Eigenvalue of 1.47 , percentage variance of $83.9 \%$ and canonical correlation of 0.77 . Function 2 with Eigenvalue of 0.23 , percentage variance of 12.2 and canonical correlation of 0.42 while function 3 has Eigenvalue of 0.07, percentage variance of 3.9 and canonical correlation of 0.25 .

The procedure for test of statistical significance involves successive testing all the discriminant functions at a time and removing the function that has the highest Eigenvalue until there are no significant functions that jointly contribute to group differences (Stevens, 2002). Test of statistical significant indicated that functions 1 through 3 and Functions 2 through 3 were significant beyond 5\% level of significance with 0.000 and 0.006 levels of significance respectively. Function 3 alone was significant at 0.319 level of significance. 
The three discriminant functions were used as the three functions were jointly significant. The implication of removing function 3 from the analysis would amount to removing it contribution to variance in the analysis. SPSS package normally indicate the numbers of discriminant functions included in analysis, and for this paper it indicated the first three discriminant functions.

In estimation subsamples, $66.7 \%$ of the total offices were predicted to be correctly classified. This represents 100 correctly classified offices out of a total number of 150 offices. The breakdown included 52 correctly classified offices out of 60 offices in Class A; 8 correctly classified offices out of 26 offices in class B, 14 correctly classified offices out of 30 offices in class $\mathrm{C}$; and 26 correctly classified offices out of 34 offices in class D. In holdout subsamples that were used to validate the classification procedure $59 \%$ of the total 100 offices were correctly classified. The breakdown included 29 offices correctly classified out of 33 offices in class A; 5 correctly classified offices out of 26 offices in class B; 7 correctly classified offices out of 13 offices in class C and 18 correctly classified offices out of 28 offices in class D.

Classification accuracies were evaluated against accuracies that could be attributed to chance occurrences. The estimated values of each of the maximum and proportional chance criteria were increased by a quarter of their values. The increased estimated values are $50 \%$ and $35 \%$ for maximum and proportional chance criteria respectively for estimation subsamples. The values were lower than $66.7 \%$ of estimation subsamples classification accuracy. The estimated Press's Q statistics for estimation subsamples is 139 , which is greater than figure of 6.63 that represents chance occurrence accuracy value

For holdout subsamples, increased estimated values are $41 \%$ and $34 \%$ for maximum and proportional chance criteria respectively. The values were lower than $59 \%$ of holdout subsamples classification accuracy. The estimated Press's Q statistics for holdout subsamples is 62 , which is greater than figure of 6.63 that represents chance occurrence accuracy value. It could be concluded that the rent-interval classification is valid and adequate since all the values of classification accuracies of both estimation and holdout subsamples were greater than all standard values of accuracies that could be attributed to chance occurrences.

Class B offices have the highest misclassification cases in both estimation and holdout subsamples with $69.3 \%$ and $80.8 \%$ respectively. Class $\mathrm{C}$ has as the second highest number of misclassified cases with $53.4 \%$ and $46.2 \%$ in estimation and holdout subsamples respectively. Class D offices ranked third in terms of misclassification rate in estimation subsamples and holdout subsamples with $23 \%$ and $35.7 \%$ respectively. Class A offices have the lowest cases of misclassification in both estimation and holdout subsamples with $13.3 \%$ and $12.1 \%$ respectively.

The misclassification cases might be the results of using a single variable in rent-interval classification as against many independent variables in discriminant analysis which might make discriminant analysis to predict class membership more accurately than rentquality classification. Analysts may adjust the classification based on discriminant analysis prediction of membership. These results provided answer to the initial question on the extent to which the results of classification could represent optimal classification. Next section presents the discussion of the results of rent interval classification as the classification procedures was considered to be valid.

\section{DISCUSSIONS AND CONCLUSION}

The results of classification indicated that rental level has a direct relationship with 
level of office quality and that the rational and irrational behaviours of market participants should be taken into consideration in rent-interval classification. These findings supported the initial theory that if rent is a true reflection of office quality therefore office quality classification based on rent interval should be able to identify high offices quality classes with high rent and vice versa. The findings is similar to description office quality classes in literature that described high quality offices as those with rent above average market rent and low quality offices as those with rent below average market rent (BOMA, 2011; Downs, 1980; Graham and Bible, 1992; Ling and Archer, 2006; Chung and Hui, 2009). The four office quality classification schemes found in this study corresponded with reported office classes A-D by Dunse and Jones (2002) for Glasgow office market, Oven and Pekdemir (2006) for Istanbul office market and Property Council of New Zealand (nd).

These findings reflect the variations in quality of offices in the office market of Federal Capital City of Abuja Nigeria. Class A offices in Abuja are purpose built offices with modern designs and facilities with few of them located in the Central Business District (CBD), Maitama District and majorly located at Wuse District. This has made Wuse District the major commercial centre in Abuja. They are owned by private individuals and corporate organisations. Class B offices are of little lower quality than Class A offices in term of facilities and design developed by both public authorities and private developers. Commercial class B office developed by public authorities dominated the CBD as the cost of land is very high for private developers in the CBD.

This finding corresponded with Dermisi and McDonald (2010) description of office Class A as having the highest quality in downtown Chicago with quality decreasing from this highest class to the lowest class. This could have ac- counted for higher rent on private developed offices as compared to commercial public authorities' offices apart from little differences that could be attributed to quality variations offices in CBD. Other districts with significant numbers of class B offices are Utako and Jabi districts that are witnessing new office development in recent times.

Classes A and B offices qualities corresponded with description of office class A in three office quality classes categories found in literature (Roberts, 1986; Thrall, 2002; Imperiale, 2006; Niemira, 2009; Winnel, 2010) by having the better qualities of design, layout and services than class $\mathrm{C}$. The offices are also built between 1991 and 2010 which made them to be similar to Dunse and Jones (2002) description of class A offices in four classes scheme as "those offering high quality space and constructed within the last $15-20$ years".

Class C offices are with quality of facilities and design lowered than class $\mathrm{B}$ offices. They are majorly found in Wuse, Utako and Jabi districts that cater for the needs of different office users. Class C offices description corresponded with the description of qualities of class B offices in three class's scheme in the literature by have average qualities of design, layout and services and also within the age range of $15-20$ years as in Dunse and Jones (2002). Class D offices are old offices that offer adequate office space for lowest category of office users. They are majorly old office buildings located at Gariki district built in 1991 when the capital of Nigeria was moved from Lagos to Abuja. This category of offices could also be found in some part of Wuse, Utako and Jabi districts that are not as old as the one in Gariki Districts but built to meet the needs of below average office users. This finding corresponded with description of class $\mathrm{C}$ offices in three scheme classes in office classification literature as the offices in class D has the lowest quality of design, layout and services. 
This paper was aimed at proposing theoretical framework and empirical method of using rent intervals to identify office quality classes. It was also aimed to use the proposed empirical approach to classify offices in the Federal Capital City of Abuja Nigeria to quality classes and to validate the classification procedures. The theoretical framework and empirical approach were able to identify four office quality classes in the study area. The validation of the procedures used authenticated the procedures as the classification accuracies were greater than accuracies that could be attributed to chance occurrences.

This paper has extended theoretical and empirical approaches adopted in office quality classification by incorporating theory of behaviour of market participants and validation of classification procedures using the capital city of Nigeria. There is tendency that other cities with different levels of development may produce different results with these approaches. Moreover, generalisation of this study could be limited to the study area as the samples could not cover wide geographical area due to lack of data and cost of data acquisition. Therefore it is recommended that the approaches used in this study should be replicated in other cities with different levels development and wider geographical area to test the consistency of the approaches.

\section{REFERENCES}

Adair, A. S., Berry, J. N. and McGreal, W. S. (1996) Hedonic modelling, housing submarkets and residential valuation, Journal of Property Research, 13(1), pp. 67-83. http://dx.doi.org/10.1080/095999196368899

Baum, A. (1994) Quality and property performance, Journal of Property Valuation and Investment, 12(1), pp. 31-46. http://dx.doi.org/10.1108/14635789410050494

Bajic, V. (1983) Urban housing markets modelling: short-run equilibrium implications, Real Estate
Economics, 11(3), pp. 416-438.

http://dx.doi.org/10.1111/1540-6229.00299

Bishop, J. (1977) CRIG analysis, Bulletin of Environmental Education, 73, pp. 3-8.

BOMA (2011) Building class definitions. [Online] Building Owners and Managers Association (BOMA). Available at: http://www.boma.org/ Resources/classifications/Pages/default.aspx [accessed 22 March 2011]

Chung, W. and Hui, Y. V. (2009) A study of energy efficiency of private office buildings in Hong Kong, Energy and Buildings, 41(6), pp. 696-701. http://dx.doi.org/10.1016/j.enbuild.2009.02.001

Cooper, D. and Schindler, P. (2006) Business research method. $9^{\text {th }}$ Edition. New Delhi: Tata McGraw-Hill Education.

Corona, C. (2003) Variety of factors help office buildings make grade, Tampa Bay Business Journal, April 11, 2003, Available at: http://southflorida. bizjournals.com/tampabay/stories/2003/04/14/ focus $2 . \mathrm{html}$ ? $\mathrm{q}=$ office $\% 20$ grades $\% 20$ classification [accessed 8 May 2009]

Daud, M. N., Adnan, Y. M. and Aziz, A. A. (2010) Developing the matrix for Malaysia's office classification model. In: Proceedings of the $4^{\text {th }}$ NAPREC conference, $29^{\text {th }}$ September 2010, pp. 27-45. [Online] Available at: www.inspen.gov. my/inspen/v2/wp-content/uploads/2009/08/Office-Classification.pdf [accessed 22 March 2010]

Daud, M. N., Adnan, Y. M., Mohd, I. and Aziz, A. A. (2011) Developing a model for Malaysia's office classification, Building Research \& Information, 39(3), pp. 301-313. http://dx.doi.org/10.1080/09613218.2011.552271

Dermisi, S. and McDonald, J. F. (2010) Selling price/ sq. ft. of office buildings in downtown Chicago - how much is it worth to be an old but class A building? Journal of Real Estate Research, 32(1), pp. 1-21.

Downs, J. (1980) Principles of real estate management, $12^{\text {th }}$ edition. Chicago: Institute of Real Estate Management.

Duggan, E. (2003) Making the office grade isn't real estate science, South Florida Business Journal, August 7, 2003. [Online] Available at: http://www.bizjournals.com/southflorida/ stories/2003/08/11/focus 4 .html?page=all [accessed 8 May 2009] 
Dunse, N. and Jones, C. (2002) The existence of office submarkets in cities, Journal of Property Research, 19(2), pp. 159-182. http://dx.doi.org/10.1080/09599910210125214

Dunse, N., Leishman, C. and Watkins, C. (2001) Classifying office submarkets, Journal of Property Investment and Finance, 19(3), pp. 236-250. http://dx.doi.org/10.1108/14635780110387592

Everitt, B. S. (1993) Cluster analysis. London: Edward Arnold.

Fuerst, F. (2007) Office rent determinants: a hedonic panel analysis, MPRA Working Paper, University of Reading. [Online] Available at: http:// mpra.ub.uni-muenchen.de/11445/ [accessed 15 August 2009]

Graham, M. F. and Bible, D. S. (1992) Classifications for commercial real estate, The Appraisal Journal, 60(2), pp. 237-246.

Hair, J. F., Black, B., Babin, B., Anderson, R. E. and Tatham, R. L. (2005) Multivariate data analysis, $6^{\text {th }}$ edition. New Jersey: Prentice Hall.

Ho, D., Newell, G. and Walker, A. (2005) The importance of property-specific attributes in assessing CBD office building quality, Journal of Property Investment and Finance, 23(5), pp. 424-444. http://dx.doi.org/10.1108/14635780510616025

Johnson, R. A. and Wichern, D. W. (2002) Applied multivariate statistical analysis, $5^{\text {th }}$ edition. New Jersey: Pearson Education.

Imperiale, R. (2006) Getting started in real estate investment trusts. New Jersey: John Wiley and Sons, Inc.

Ling, D. and Archer, W. (2006) Real estate principle: a value approach, $2^{\text {nd }}$ edition. New York: McGraw-Hill/Irwin.

Nappi-Choulet, I., Maleyre, I. and Maury, T. P. (2007) A hedonic model of office prices in Paris and its immediate suburbs, Journal of Property Research, 24(3), pp. 241-263. http://dx.doi.org/10.1080/09599910701599290

Niemira, M. P. (2009) Making the grade the value of shopping center, Retail Property Insights, 16(2), pp. 65-68.

Oven, V. A. and Pekdemir, D. (2006) Office rent determinants utilising factor analysis-a case study for Istanbul, Journal of Real Estate Finance and Economics, 33(1), pp. 51-73. http://dx.doi.org/10.1007/s11146-006-8274-5

Property Council of Australia (2006) Office building quality: sustainability judge. [Online] Available at: http://www.propertyoz.com.au/Article/ Resource.aspx?media $=501$ [accessed 8 May 2009]

Property Council of New Zealand (nd). Quality grading matrix and retail classifications. [Online] Available at: http://www.propertynz.co.nz/ files/Research/Quality\%20Grading\%20Matrix. pdf [accessed 8 May 2009].

Roberts, D. F. (1986) Marketing and leasing of office space. Revised edition. Chicago Illinois: The Institute of Real Estate Management.

Rothenberg, J., Galster, G., Butler, R. and Pitkin, J. (1991) The maze of urban housing markets: theory; evidence, and policy. Chicago: The University of Chicago Press.

Rider Hunt (1991) Building quality assessment. Sydney: Rider Hunt.

Sharma, S. (1995) Applied multivariate techniques. New York: John Wiley and Sons, Inc.

Stevens, J. P. (2002) Applied multivariate statistics for the social sciences, $4^{\text {th }}$ edition. New Jersey: Lawrence Erlbaum Associates, Inc.

Tabachnick, B. G. and Fidell, L. S. (2006) Using multivariate statistics, $5^{\text {th }}$ edition. Allyn \& Bacon.

Thrall, G. I. (2002) Business geography and new real estate market analysis. Oxford: Oxford University Press.

Verde, R. and Irpino, A. (2007) Dynamic clustering of histogram data: using the right metric. In: Brito, P., Bertrand, P., Cucumel, G. and Carvalho, F. (eds.), Selected contributions in data analysis and classification. Studies in classification, data analysis, and knowledge organization. Springer Berlin Heidelberg. Part I, pp. 123-134.

http://dx.doi.org/10.1007/978-3-540-73560-1_12

Vilnai-Yavetz, I., Rafaeli, A. and Yaacov, C. S. (2005) Instrumentality, aesthetics, and symbolism of office design, Environment and Behavior, 37(4), pp. 533-551.

http://dx.doi.org/10.1177/0013916504270695

Winnel, M. (2010) Why quality matter in property investing, Property Insights, April, 2010. 
[Online] Available at: http://digitalinsights. ampcapital.com.au/Redirect.aspx?click url=http $\% 3 \mathrm{a} \% 2 \mathrm{f} \% 2 \mathrm{fwww}$. ampcapital.com. au\%2fK2DOCS\%2fsite_ampci\%2fF32A84395CF7-4B66-B41B-2E0FD5CF3668\%2f2010-
April_Property-investing-insights-paper. pdf\%3fDIRECT [accessed 22 March 2011]

Wyatt, P. and Ralphs, M. (2003) GIS in land and property management. London: Spon Press. 